\title{
EL BESTIARIO \\ DE GABRIEL GARCÍA MÁRQUEZ
}

La bibliografía sobre Gabriel García Márquez y su obra es ya inmensa ${ }^{1}$. Puede decirse, sin que mucho se yerre, que el escritor colombiano es uno de los pocos que, vivo, integraron la categoría de los "clásicos", en el sentido etimológico de la palabra y en el de "principal, notable".

Quisiera analizar un rasgo estilístico de dicha obra, que es, según pienso, un elemento esencial del mundo novelesco de García Márquez. Hasta ahora, que yo sepa, no ha realzado suficientemente la crítica el papel que desempeñan los animales en las obras del novelista. Real o mítica, bajo la forma de adornos o vertida en tropos, la fauna es omnipresente en dicha obra: cunde y se multiplica, acompaña o destruye a los hombres de los cuales también puede ser representación simbólica. El bestiario, a veces, estructura por si mismo algún cuento o novela: tal o cual animal "fetiche" (iba a decir totémico) está en el mismo centro del relato, alrededor del cual giran, atrayéndose o alejándose, los otros componentes. El estudio descriptivo que propongo abarca las obras más significativas de Gabriel García Márquez (cuentos y novelas a partir de La hojarasca, 1955) ${ }^{2}$.

\section{Animales ReAles ${ }^{3}$}

Desde La hojarasca hasta el libro de cuentos más recientes de García Márquez, pululan los insectos y toda clase de bichos menu-

1 Hasta 1971, tenemos la bibliografía bastante completa recogida por $M$. Vargas Llosa en Garcia Márquez, historia de un deicidio, Barrai, Barcelona, 1971.

2 Remito a las siguientes ediciones. Me referiré a ellas mediante la abreviatura más el número de la página: La hojarasca, 3a ed. Sudamérica, Buenos Aires, 1969 (= Hoj); Isabel wiendo llover en Macondo. Estuario, Buenos Aires, 1969 (=Is); El coronel no tiene quien le escriba. 5a ed. Era, México, 1968 (= Cor); Los funerales de la Mamá Grande. 9a ed. Sudamericana, Buenos Aires, 1971 (=Fun); La mala hora. 2a ed. Sudamericana, Buenos Aires, 1968 $(=M h)$; Cien años de soledad. Sudamericana, Buenos Aires, 1969 (=CAS); La increible y triste historia de la cándida Eréndira y de su abuela desalmada. Barral, Barcelona, 1972 (=Er).

3 El lector se enterará rápidamente de que las categorías que propongo tienen sólo un carácter metodológico: un elemento animal bien puede pertenecer a la vez a dos categorías o estar en vilo entre una y otra. 
dos: lombrices (Cor, 9; CAS, 61, 289), polilla y piojos (Hoj, 128; Cor, 10-11; Fun, 84; CAS, 63, 80, 81; Er, 101), moscas triangulares (Cor, 26), cigarras (Hoj, 83, 85; Fun, 66; $M$ h, 78, 99, 100), congorochos y arañas $\left(H o j, 76^{4} ; F u n, 24\right)$, etc. Los hombres tienen que protegerse contra los zancudos ${ }^{5}$, que son una verdadera obsesión para el padre Ángel en La mala hora:

Los zancudos lo asaltaron.

El vaho de los zancudos lo envolvió al encender la luz del cuarto.

En la habitación oscura empezaban a zumbar los zancudos.

. . la primera oleada de zancudos penetró por el balcón.

... cazando los mosquitos que habían sobrevivido al insecticida... ${ }^{6}$.

También en esta novela aparecen las hormigas voladoras $(M h$, 192-193) que desempeñan un papel esencial en Cien años de sole dad: invaden el aire cuando muere el coronel Aureliano Buendía; las hormigas coloradas van arrasando la casa familiar después de la muerte de Úrsula, sin respeto por la habitación del gitano Melquíades que permaneció mágicamente intacta durante años ( $C A S$, 228-229). Los últimos de la familia Buendía luchan obsesivamente, pero en vano, contra ellas: Amaranta Úrsula y el último Aureliano casi son devorados por las hormigas carnívoras, pero resisten "construyendo las últimas trincheras de la guerra inmemorial entre el hombre y las hormigas" (CAS, 345). Estas vencen y se llevan al último brote de la familia: "El primero de la estirpe está amarrado en un árbol y al último se lo están comiendo las hormigas" (CAS, 349).

Las hormigas de Cien años de soledad, pues, se convierten en animales míticos, actúan de manera verosímil aunque horrorosa. Ya encontramos algo parecido en La hojarasca, novela en la cual un ataúd lleno de moscas es, para el niño, la representación de la muerte. Las moscas, pues, en tanto reales, están en vía de simbolización:

Cuando descubro que hay moscas en la habitación comienza a torturarme la idea de que el ataúd ha quedado lleno de moscas... es el tropel de las moscas golpeando, ciegas, contra las paredes del ataúd y la cara del muerto... "Estarás asi. Estarás dentro de un

4 Ahí aparece una "pareja de congorochos, macho y hembra", simbólica y quizá irreal según el contexto.

5 "Espectáculos insólitos como el de los caballos bajo los mosquiteros", pues aquí caballos y zancudos, por lo "insólito" de la situación y por la asimilación humana de aquéllos, integran tanto la categoría "animales reales" como la de los "míticos" Hoj, p. 40; también Cor, 25, 32; Fun, 52, 107, 142; CAS, 30, 97, 206, 224.

${ }_{6}^{6} M h, 8,21,42,63,201$. Es de notar que en La hojarasca son moscas las que acosan al Padre Ángel (p. 20). 
ataúd lleno de moscas. Apenas vas a cumplir once años, pero algún dia estarás asi, abandonado a las moscas dentro de una caja cerrada" (Hoj, 22).

Sin embargo, se destaca Cien años de soledad entre las demás obras de García Márquez por la abundancia impresionante de toda clase de animales. Así, en el campo de los bichos menudos aparecen los insectos luminosos que encuentran los fundadores de Macondo (CAS, 17, 349), cucarachas (ibid., 283-284) ${ }^{7}$, grillos $^{8}$, gusanos ${ }^{9}$, chinches (ibid., 213).

Hay que poner aparte las mariposas, que pueden disecarse (ibid., 63-99) y sobre todo pueden ser señal, anuncio de otra cosa: Mr. Herbert cazando mariposas adelanta la instalación de la compañía bananera (ibid., 196) ; una nube de mariposas amarillas acompaña, lo veremos, a un héroe de la novela.

Los alacranes figuran en varios episodios de la obra. En el de los amores de Meme y Mauricio, tienen, como las mariposas, carácter simbólico: "Esa noche, la guardia derribó a Mauricio Babilonia cuando levantaba las tejas para entrar en el baño donde Meme lo esperaba, desnuda y temblando de amor entre los alacranes y las mariposas..."10.

Mencionemos igualmente las arañas disecadas por el esposo de Amaranta Ưrsula:

[Gastón] se dedicó a capturar y disecar cuanto insecto aborigen encontraba en los contornos, que remitía en frascos de mermelada a su antiguo profesor de historia natural de la universidad de Lieja, donde había hecho estudios avanzados de entomología, aunque su vocación dominante era la de acronauta ${ }^{11}$.

7 Notemos también las cucarachas de mar, p. 84.

${ }^{8} C A S, 101,226$; anteriormente y como señal de vida en Hoj, 91, 93-94.

9 Los gusanos hallados por Úrsula en la olla de la leche son un falso presagio de la muerte del coronel Aureliano Buendía (CAS, 156). En los recuerdos de Úrsula, aparece su padre, Aureliano Iguarán, el cual había compuesto una oración para que "se achicharraran y se cayeran los gusanos de las vacas", p. 289. Anteriormente en Fun, 81, los gusanos del queso concretan la decadencia de la casa Montiel, y posteriormente, en Er, 65, los gusarapos de un pozo representan la realidad miserable frente a lo imposible ("El dia en que haya sábalos en vez de gusarapos en los pozos...").

10 CAS, p. 248; véanse también pp. 86, 201, 216, 338.

$11 C A S$, p. 320. Es curiosa esa mención de la universidad de Lieja (donde estudió y enseñó el que firma estas líneas). Dicha universidad sí tuvo y tiene aún una gran escuela de biología, aunque no dedicada especialmente, que yo sepa, al estudio de la entomología. Se trata probablemente de un recuerdo o alusión muy personal de García Márquez. Véanse también pp. 90. $\$ 10$. 
Huelga decir que éste es el único texto entre las obras de ficción de García Márquez que mira los animales en tanto objeto de ciencia $^{12}$.

Los personajes de las obras de nuestro escritor viven con animales familiares, útiles y más o menos domesticados. En primer lugar están las aves de corral: patos, gallinas, pollos, pavos, pavos reales y codornices ${ }^{13}$. Destacamos los gallos, sobre todo los de pelea, que, en El coronel no tiene quien le escriba y Cien años de soledad, son verdaderos protagonistas y se alzan a la categoría de animales mí$\operatorname{ticos}^{14}$.

Los vecinos del Macondo primitivo se dedican a la cría de puer$\cos (\mathrm{Hoj}, 39)$; en un cuento de Los funerales de la Mamá Grande (p. 84), unos cerdos rosados simbolizan la opulencia de París. En La mala hora aparecen puercos que luego integran una expresión metafórica al mismo tiempo familiar y ambigua: fango.

Ahora había ropa puesta a secar y dos cerdos revolcándose en el

-Pueden hasta sembrar -dijo el alcalde.

La mujer respondió sin levantar la cabeza: "se lo comen los puer$\cos ^{\prime \prime}$ (p. 77).

En Cien años de soledad, el lechón es alimento muy apreciado y los cerdos figuran como premio en las rifas organizadas por Aureliano Segundo y Petra Cotes ${ }^{15}$.

En las dos primeras novelas de García Márquez, se asocian los gatos con la gente de los circos que tiene fama de robar estos animales para alimentar las fieras (Cor, 93-94; $M h, 88-89$ ), mientras en Los funerales de la Mamá Grande, uil gato blanco tiene una función simbólica y desempeña el papel de protagonista mudo (Fun, 31, 49; también 67, 90).

Las palomas pertenecen a un campo entre real y metafórico: en La mala hora (pp. 9 y 17), por ejemplo, aparecen en la expresión

12 Para completar el cuadro de los bichos menudos en las obras de Garcia Márquez, señalo "la minúscula actividad de los insectos" en $(H o j, 60)$, los lagartos (ibid., 109, 128, aquí signo de la decadencia de Macondo). En Fun se evocan moscas (p. 104) y moscardones (p. 106); en Er, 83, tarántulas y escolopendros figuran en una lista de animales ponzoñosos.

13 Hoj, 29; Cor, 43, 64, 67; Fun, 46 (gallina como alimento) ; 104-105 (las gallinas del pueblo del viajero se convierten en protagonistas); $M h, 29,31,35$, $171 ;$ CAS , 30, 135, 188, 248, 259, 328; 297 (gallina sacrificada en una especie de rito mágico); 102 (patos siliestres); 197 (pavorreales y codornices son animales de importación, de lujo).

14 Galios, sin más, los hay en Fun, 29, 39, 108 (cantan al amanecer); Mh, 167-168.

15 CAS, 14 (manteca de cerdo), 85, 188, 286, 298; véase también Fun, 128, 135 y $\mathrm{Er}, 123$. 
"el aire cargado de una porquería de palomas", mientras en Cien años de soledad (p. 31) siempre se relacionan con la risa de Pilar Ternera que las espanta.

Mulas, mulos, caballos, burros, vacas, toros y bueyes pueblan el paisaje rural de las obras de García Márquez ${ }^{16}$. A veces tienen una función especial: un mulo puede servir como moneda $(C A S, 9)$; las mulas llevan el correo $^{1 \tau}$, los burros robados por don Sabas se convierten rápidamente en símbolo de su insaciable codicia. Al decir que José Arcadio Buedía era capaz de derribar un caballo, el escritor alcanza el límite de la expresión metafórica $(C A S, 55)$.

Los perros corren sin parar por las calles del "pueblo" y de Macondo; se diferencian por el uso que de ellos hace el hombre, y también por la raza: perros de asalto, perros rastreadores, perros de presa, perros montunos, etc. ${ }^{18}$. ..."Feroces perros alemanes" acompañan simbólicamente a los explotadores gringos de Macondo (CAS, 196, 219 ;bailan!). El recuerdo de un acontecimiento lamentable en el cual interviene un perro "con mal de rabia" ilustra la indignación del coronel Aureliano Buendía (CAS, 206). Ha de destacarse la llegada de Mister Brown en el primer automóvil que vio la gente de Macondo: era "un convertible anaranjado con una corneta que espantaba a los perros con sus ladridos" (loe. cit.); la metáfora remite al propio objeto que sufre el ruido de la corneta.

Pájaros invaden el aire de Macondo: los cazados por los niños de La hojarasca (pp. 53, 57), los enjaulados por la viuda de Asís, y los de Úrsula cuyo concierto guía a los gitanos de Melquíades hacia el pueblo recién fundado y que huyen cuando se acerca el Judío Errante ${ }^{19}$. También están los canarios que Amaranta Úrsula trata en vano de conservar, los que viven en Los funerales de la Mamá Grande ${ }^{20}$, los alcaravanes cuya función principal es, según parece, anunciar la hora, los loros, turpiales, petirrojos, guacamayas, golon-

16 Mulas, se convierten en señal complementaria de "la hojarasca", Hoj, 9, 39, 40, 42, 45, 49; bestias de caballeriza, con una connotación social por ser señal de riqueza, ibid., 54; la huella del último buey, símbolo de una calle desierta, ibid., 61; carretas de bueyes cargadas de racimos verdes, Fun, 11; novillos, ibid., 82, 128, 130, 131; se sacrificaban reses para los cumpleaños de la Mamá Grande, anticipación de los sacrificios de los animales en CAS, 135, 136; Mh, 12, 92, 85 reses, 86 terneros, 177 ganado; CAS, 92, 150, 155, 282, 286-287; 12, 76, 83, 117, 171, 203, 250; 38, 56, 72, 103, 271, 188; Er, 126.

$17 \mathrm{Hoj}, 20 ; C A S, 11,17,63 ; E r, 109 ; M h$, 101 ss., 198; en $E r, 63$, pide una mujer un burro para traer agua; la compra de un burro es el primer paso hacia el bienestar de la abuela desalmada (p. Ill); cuando tiene una carreta tirada por bueyes, ya está en plena opulencia (p. 148).

18 Hoj, 109; Fun, 58; Mh, 58, 87; CAS, 24, 92, 102, 103, 117, 132; Er, 29, 76.

$19 \mathrm{Mh}, 36-38,96,171,198 ; C A S, 16,40,97,119$.

20 Fun, 66; CAS, 318-320; también vivían los canarios en las jaulas de Ursula poco después de fundarse Macondo; es relevante el contraste. 
drinas, alondras ${ }^{21}$ Merecen una mención especial los gallinazos por el papel dramático y la función simbólica que desempeñan, par. ticularmente en La hojarasca, donde es tema recurrente la visión de dichas aves devorando un cadáver, desde el epígrafe: “. . el cadáver de Polinice lo dejen para sabrosa presa de las aves que se abalancen a devorarlo" (de Antigona):

...hoy no habría en el pueblo una persona dispuesta ni siquiera a echar el cadáver a los gallinazos (p. I7).

Es lo único que necesito para que no me coman los gallinazos (p. 125) ${ }^{22}$.

Por supuesto hay animales de circo (leopardo, elefante, oso, dromedario), recuerdo probablemente autobiográfico ${ }^{23}$. Hay ratas y ratones, que en "Rosas artificiales" (Fun, 120; también 45) y en La mala hora tienen un poder obsesivo parecido al de los zancu$\operatorname{dos}^{24}$; tortugas ${ }^{25}$; micos y monos (Fun, 142; Mh, 39, 59; CAS, 17, 21), culebras $^{26}$, camaleones $(M h, 121)$, sapos $(M h, 126 ; C A S, 227$, 283), chivos ${ }^{2 \tau}$. En Cien años de soledad aún se amplía esta fauna ya prodigiosa con caimanes, salamandras, calamares, tigres, caracoles, almejas, murciélagos, conejos, víboras ${ }^{28}$. Asombrosa es la enumeración y queda, sin duda alguna, incompleta. Habría que añadir todos los animales muertos que estorban en las calles de

21 Alcaravanes que anuncian la hora en $H o j, 127$ y 132-I33 (sienten el olor de un cadáver), íun, 105; $M h, 69,144,197 ; C A S, 101$; véase también Fun, 74. Otros pájaros y aves: Hoj, 55, las golondrinas son protagonistas de un episodio; Fun, 68 ss.; $M h, 59$ (loros) ; $C A S, 17,39,40,54,69$, 281, etc...; Er, 74, 77: "El aire cotidiano de los pelícanos", expresión al límite de la metáfora; cf. ibid., 158: "se iba despertando el aire de los pájaros"; Blacamán se ve "esculpido en mármol ecuestre y cagado de golondrinas como los padres de la patria", con intención satírica evidente, ibid., 92; 113 ss., 119; 134 pájaros enjaulados ocultan un tráfico de contrabando.

22 Véase tambićn Fun, 23, "gallinazos pensativos"; suscitan el proceso de memoria asociativa muy a lo Proust, p. 99; también siguen los funerales de la Mamá Grande, p. 146; $M h, 88,119 ; C A S, 219-229$.

23 Cor, 93; $M h, 82,91,126,137,185 ; C A S, 229$; véase L. Harss, "Gabriel García Márquez o la cuerda floja”, en Mundo Nuevo, 1966, núm. 6, p. $67 a$.

$24 M h, 22,44,47,109-110,164,183,202-220$ y en $C A S, 290,303,340$; en $E r, 155$, Ulises trata de asesinar a la abuela con "una libra de veneno para ratas".

$25 M h, 121 ; E r, 42$ : tortugas de mar, fantásticas por el contexto.

26 Para García Márquez la culebra es el animal totémico del curandero; aparece por primera vez, que yo sepa, en Cor, 72, 96 y después en Fun, 144; $M h, 102,109$; y desempeña un papel central en "Blacamán", Er, 83; véase también pp. 33, I46; en $C A S, 27$ hay un "caldo de culebras".

$27 \mathrm{CAS}, 9 ; \mathrm{Er}, 60$ (alimento), 65, 113, 126.

$28 C A S, 16,17,23,63,102,117,167,272,303$, etc. 
Macondo, la lluvia de pájaros muertos, fantástica pero verosímil, que es una reiteración significativa en la obra de García Márquez publicada hasta hoy ${ }^{29}$, y todos aquellos cadáveres de gatos, vacas y caballos ${ }^{30}$. Deberíamos hablar de los animales en los platos y remedios compuestos por Úrsula (CAS, 33, 39, 43, 232, 268). También merecería un estudio detenido el vínculo entre algunos animales y personajes o situaciones. Resaltarían especies de animales totémicos o fetiches y funciones simbólicas tal como la que une al padre Ángel de La mala hora (p. 59) a los cadáveres de un gato y de una vaca, o aquélla que plasma la muerte del pueblo en la agonía largamene descrita de una vaca (Isabel viendo llover en Macondo).

La invasión de animales en las obras de García Márquez se da sobre todo en sus dos últimas novelas publicadas y se acentúa cada vez más la tendencia a la observación del mundo animal. $\mathrm{Al}$ bestiario de Cien años de soledad le faltaba poco para cubrir la mayoría de las especies animales, exceptuando los peces mencionados sólo como alimento: sardinas portuguesas, arenques secos (CAS, 87, 338). Pero en el último libro de cuentos, de ambientación diferente, como ya se ha notado ${ }^{31}$, asistimos a un verdadero asedio de los productos del mar: cangrejos, mariscos, pescados muertos, medusas, peces ciegos, tiburones, delfines, mantarrayas, esponjas, pargos, ...32. También aparece por primera vez en el cuento de Eréndira (pp. 98-99, 101-103, 14) "un avestruz raquítico", que funciona como símbolo y leitmotiv. Así se renueva de un libro a otro la fauna literaria de García Márquez, ampliándose cada vez más.

\section{Decoración ANIMAL}

Los hombres, acompañados -y muchas veces acosados- por esta fauna omnipresente, imitan naturalmente las formas animales en

29 En el cuento "Un día después del sábado", Fun, 90 ss.; $M h, 49 ; C A S$, 119; véase L. Harss, art. cit., p. 74a: "Si los pájaros que caen en el cerco de alambre de la viuda Rebeca recuerdan las ratas de $L a$ peste de Camus, es, dice García Márquez, porque ese es el libro que a mi me hubiera gustado escribir".

${ }_{30} M h, 59,80,86,89,99 ; C A S, 271,272,324 ; E r, 11$; invasión de cangrejos paralela a la lluvia de pájaros muertos en obras anteriores, p. 23. "[Blacamán] tiraba por los rincones pedazos de lagartos y gavilanes podridos para que el aire del calabozo se acabara de envenenar. [...] me llevó el cadáver de un conejo..." (p. 90), aquí pasa el relato al nivel fantástico por la resurrección del conejo.

31 M. Vargas Llosa, op. cit., pp. 618-621.

$32 \mathrm{Er}, 11,24,40,42,49,50,53,54,74,75,77$. Se mencionan rápidamente pescados en Hoj, 54. Es de notar que "El mar del tiempo perdido" (Er, 21-45), donde aparecen por primera vez los cangrejos molestos, fue escrito en 1961. 
los objetos que inventan y fabrican. Sin embargo, en las primeras obras de García Márquez tales objetos son poquísimos: notamos en La mala hora una pajarita de papel para los niños - por otra parte integrada en una frase comparativa- y unas baldosas con un mismo pavo real anguloso $(M h, 65,138)$. La una y las otras vuelven a aparecer en el último libro de cuentos del escritor colombiano:

Mientras hablaba [el senador], sus ayudantes echaban al aire puñados de pajaritas de papel, y los falsos animales cobraban vida, revoloteaban sobre las tribunas de tablas, y se iban por el mar $($ (Er, 61)

A la vez que representan simbólicamente la falsedad de las promesas electorales del senador, las pajaritas de papel son parte de la corriente fantástica que impera en los textos de Eréndira: cobran realmente vida más allá de la metáfora. Lo mismo ocurre con la mariposa de papel hecha por el mismo senador (ibid., 65-66). En cuanto al "baño adornado de pavorreales repetidos", aparece al principio del cuento que da el título al libro y es reemplazado por "una bañera de peltro con patas de león" en el resto del relato (ibid., 97, 135).

Cien años de soledad fue el primer texto de García Márquez que ofreció abundantes elementos de esta fauna artificial con los animalitos de caramelos, gallitos y peces azucarados fabricados por Úrsula $a^{33}$, los monos acróbatas, los caballos trotadores [...] la rica y asombrosa fauna mecánica que llevaba Pietro Crespi (CAS, 70), los dibujos o pinturas de animales metamorfoseados por la imaginación: vaquitas rojas, cochinito verde, gallinitas azules (ibid., 71, $172,288)$. Hay además un oso de cuerda $^{34}$, palomas en una tarjeta postal, pavos reales bordados, taquillas en forma de cabeza de león, pulseras doradas que imitan serpientes, láminas de una enciclopedia, en especial las de los animales, una túnica bordada con dragones dorados, y sobre todo los pescaditos de oro que fabrica sin parar el coronel Aureliano Buendía ${ }^{35}$, cuando no se mete en guerras y revoluciones. El trabajo parece absurdo ya que cambia los pescaditos por monedas de oro, que sirven para hacer nuevos pescados; esta nueva tela de Penélope corresponde a la estructura circular del libro. Psicológicamente, el coronel encuentra en este trabajo minucioso fuerza para vivir y serenidad. Los pescaditos de oro alcanzan, pues, el nivel de símbolo del exilio y del retiro dedicado a la purificación interior ${ }^{36}$. Señal totémica del coronel du-

32 CAS, 39, 40, 45, 50, 53, 184, 211, 216, 260, 286, 341 .

$3 \pm \mathrm{Er}, 102$ : "Ios animales de cuerda de su infancia".

35 CAS, 63, 94, 104, 106, 115, 122, etc.

36 En último término, quizá la fabricación de los pescaditos represente el 
rante su vida, los pescaditos sirven cuando ya ha muerto: gracias a los dieciocho pescaditos que quedan, puede José Arcadio comprar los libros imprescindibles para descifrar los manuscritos de Melquíades que le revelarán el destino de la familia ${ }^{37}$.

A los adornos animales uniré el disfraz, al que recurren con frecuencia los humanos, y que integra la fauna prodigiosa de García Márquez. Surge por primera vez en La hojarasca "aquel extraño militar que en la guerra del 85 apareció una noche en el campamento del coronel Aureliano Buendía, con el sombrero y las botas adornadas con pieles y dientes y uñas de tigre" (Hoj, 120) . Era el fantástico duque de Marlborough, evocado otra vez en El coronel no tiene quien le escriba y presente a los funerales de la Mamá Grande ${ }^{38}$. En Cien años de soledad asoma de nuevo el duque "cuyo atuendo de pieles y uñas de tigre suscitaban el respeto de los adultos y el asombro de los niños" ( $C A S, 145$ ), pero también se disfraza de tigre Aureliano Segundo para participar en un carnaval sangriento.

\section{Comparaciones animales}

La crítica podría establecer otras categorías que sólo cito aquí: animales que intervienen en el recuerdo, pueblan los sueños de algunos personajes, se convierten en fetiches, tienen a veces un carácter intermedio entre lo real y el adorno ${ }^{39}$. Prefiero más bien examinar ahora huellas más profundas de la presencia del elemento animal en el propio estilo de García Márquez. Hasta ahora, hemos examinado la fauna como fenómeno, por de fuera. Los signos estilísticos (esencialmente comparaciones y metáforas) semánticamente cargados de animalidad nos permitirán tocar el corazón mismo de la obsesión y del imaginario animalista del escritor colombiano.

Las comparaciones animales de La hojarasca son numerosas y tienden a asimilar, muchas veces despectivamente, el hombre a un animal:

trabajo de escritura del novelista, con todas las consecuencias que puedan sacarse de la estructura peculiar de CAS.

37 CAS, 310. Con esta categoría de adornos animales, podrían vincularse los objetos de marfil tallados en el colmillo de un elefante (Fun, 42; $E r, 76$ ) . La integran también los pájaros bordados por la máquina de coser "que funciona[ba] conectada mediante ventosas con la parte del cuerpo en que se tuviera un dolor" $(E r, 88)$ y el "telón de fondo con un lago de cisnes inválidos" del fotógrafo, ibid., 111).

38 "El inglés disfrazado de tigre...", Cor, 26; "el duque de Marlborough

... con su atuendo de pieles y uñas y dientes de tigre", Fun, 144.

a9 Por ejemplo, "una camisa de seda tejida con el gusano vivo" (CAS, p. 311). 
...el hombre que durante seis años calentó su lecho con tanto amor y tanta humanidad como habría podido hacerlo un mulo (p. 19). Te revolcarás en la cama como un cerdo en su muladar (p. 20). ... los cuatro guajiros... seguían a mis padres... como animales amaestrados de circo (p. 39).

... su cabello liso y grueso como crin de caballo o cola de caballo (p. 40) .

...los otros... ordenados como cuatro cuervos en un caballete (p. 130) ${ }^{40}$.

Es notable la asimilación del doctor a un animal, a un burro especialmente, primero en comparaciones (Hoj, 33, 41), luego en metáforas. Una comparación, la "calavera de vaca", es signo distintivo de la cara inexpresiva del cura (ibid., 39). Encontramos comparaciones tópicas ("balaba como una oveja", ibid., 45-46) y de probable inspiración bíblica ("era como... si lo hubiéramos echado a los puercos" ${ }^{11}$ ) o comparaciones extendidas en las cuales parece que el elemento de comparación tiene más relieve que el comparado:

...irrumpe violentamente, como cuando se abre la puerta a un animal sin dirección, que corre y husmea, mudo; que rabia y araña las paredes, babeando, y retorna después a echarse, pacífico, en el rincón más fresco de la trampa (ibid., 24; véase también p. 78).

Cosas y gestos se animan mediante la comparación animal:

... un cuerpo de claridad cayó aleteando,... como un pájaro vivo. ... una risa tonta y simple que es como el hilo de agua que queda temblando en los belfos del buey, cuando acaba de beber (ibid., 53, 107).

Mientras en el breve cuento Isabel viendo llover en Macondo no hay ni una comparación animal, sólo hay tres en El coronel no tiene quien el escriba, las tres en boca del propio coronel como si fueran un rasgo típico del lenguaje del personaje (pp. 13, 18, 31). Son un tanto más numerosas en Los funerales de la Mamá Grande, pero no enseñan nada nuevo en cuanto a su estructura y $\mathrm{uso}^{42}$. Notemos sin embargo una comparación recurrente (cf. $H o j$, 40): "Tenía un cabello corto, duro y parado como los crines de un mulo..." (Fun, 65).

Con La mala hora, cambia radicalmente en cantidad y calidad

40 Véanse también pp. 54, 56, 108, 132.

$41 \mathrm{Hoj}$, 84; véanse también pp. 20, 86, metáforas de inspiración parecida.

42 Fun, 52, 54, 56, 71, 72, 87. Como voy señalando en las notas, algunas comparaciones son recurrentes en la obra posterior de Garcia Márquez. 
el estatuto de la comparación animal. Desde el primer retrato de la novela, el del padre Ángel, se vale García Márquez de una metáfora animal degradada en comparación para dibujar mejor la postura y personalidad del cura: "Era grande, sanguíneo, con una apacible figura de buey manso, y se movía como un buey, con ademanes densos y tristes"' $(M h, 7)^{43}$.

Para expresar la tensión de una situación o la angustia de un personaje, utiliza el autor el giro respirar como un gato ${ }^{44}$ que plasma todos los elementos visuales y auditivos percibidos por los protagonistas. Una frase comparativa, que desemboca en la visión de un mundo animal fantástico, sirve para que se palpe mejor la extrañeza del encuentro nocturno del alcalde con un desconocido: "En la esquina de la plaza, alguien que caminaba como si arrastrara una cola enorme le dijo algo que no comprendió" ( $M h$, 161) ${ }^{45}$.

El grito de una mujer se compara al aullido de un perro. La imagen entraña una metáfora que, por la gradación estilística, intensifica el episodio: "En este momento, aullando como un perro, la mujer apareció en la esquina. Pero cuando el alcalde apareció en la puerta lanzó un aullido ronco..." (Mh, 194-195) ${ }^{46}$.

Los personajes de La mala hora, como el coronel de la novela anterior, utilizan comparaciones en sus discursos. Pero aquí este recurso revela un rasgo psicológico: menosprecio del hombre en el alcalde y don Sabas, obsesión ridicula de los ratones en el padre Ângel:

-Está muerto -exclamó el padre, perplejo.

-Como un cochino -respondió el alcalde $(M h, 18)$.

-Dichosa juventud -exclamó finalmente el enfermo [don Sabas] -Tiempos felices en que una muchachita de dieciséis años costaba menos que una novillita (ibid., 103).

-Pon un poco de fe en tu trabajo - le había dicho [el padre Ángel a Mina]- y los ratones vendrán como corderitos hasta las trampas (ibid., 18347).

43 Claro está que la comparación resulta de la transformación de la "calavera de vaca", señal emblemática del personaje en Hoj; comparaciones con el buey en Fun, 56 y CAS, 292 (en el campo de lo fantástico).

$44 M h, 62$; se repite en $C A S, 311$.

45 Primer esbozo de los seres míticos con cola; véase el apartado $\mathrm{V}$.

46 Ya en Fun, 71: "un sonido gutural, como el ronquido de un perro..."; los perros aparecen también como elemento de comparación en CAS, 288, 317, 342; cuando se trata del sueño, se ronca "como un león" (Er, 40).

$47 \mathrm{La}$ comparación humorística de ratones con corderitos tiene aún más gracia si se piensa en la probable procedencia bíblica en boca de un cura. Cf. CAS, 100: "como el regreso del cordero extraviado". 
Cien años de soledad ofrece un sistema comparativo con términos animales desarrollado al máximo. La cantidad de este tipo de comparaciones no se explica sólo por la extensión de la novela. Responde a la necesidad interna, al dinamismo narrativo y al hecho de que el autor descubrió todas las posibilidades del proceso.

Ya notamos en La mala hora que el paso de la comparación a la metáfora alcanzaba la doble meta de la eficacia dramática y de concentración de los medios expresivos. Éste es el caso del retrato del gitano Melquíades, en el cual la comparación arranca de un juego de palabras (alas de un sombrero, alas de un cuervo) : "Usaba un sombrero grande y negro, como las alas extendidas de un cuervo..." (CAS, 13). La comparación, que sorprende al introducir una connotación siniestra, pasa a ser metáfora esencial en lo que sigue del relato: "Llevaba... el sombrero de alas de cuervo" 4 .

Los edificios de la compañía bananera, apartados de Macondo, se presentan primero "como un gigantesco gallinero electrificado" (CAS, 197). Luego son metafóricamente "el gallinero electrificado" o "alambrado" (CAS, 206). Puede darse también el movimiento inverso: de la metáfora se pasa a la comparación, como lo vimos en el retrato del padre Ángel. Así se nos habla primero de los aullidos de gata feliz de Amaranta Úrsula (CAS, 325) ; la comparación correspondiente aparece después en el relato que hace Aureliano de sus relaciones con una prostituta: "Le contó con cuánta ansiedad le pedía a Nigromanta que chillara como gata..." (ibid., 332). En este caso la degradación estilística parece conformarse a una caída sustancial.

Algunas fórmulas comparativas de Cien años de soledad merecen un comentario especial. Podríamos hablar de una comparación elevada al cuadrado en la descripción siguiente de una escena orgiástica:

A las seis de la mañana salieron desnudos del dormitorio, vaciaron la alberca y la llenaron de champaña. Se zambulleron en bandada, nadando como pájaros que volaran en un cielo dorado de burbujas (ibid., 315) .

Los cuatro niños mayores nadando en el baño de champaña, suscitan la imagen de peces, pero las burbujas que estallan en la superficie del vino entrañan la de un cielo dorado; los niños, pues, no se parecen más a peces sino a pájaros que nadan. Estamos de nuevo en la frontera de lo fantástico.

La comparación animal subraya la postura de un personaje. La más emocionante, sin duda, es la que asimila al coronel Aureliano

48 CAS, 161; véanse también 225, 290, 301. 
Buendía, este indomable revolucionario, a un pollo, a la hora de su muerte: "Metió la cabeza entre los hombros, como un pollito, y se quedó inmóvil con la frente apoyada en el tronco del castaño" (ibid., 229).

Al final de la novela, el actuar de los personajes se bestializa:

Aureliano ocupaba la mañana en descifrar pergaminos, y a la hora de la siesta iba al dormitorio soporifero donde Nigromanta lo esperaba para enseñarlo a hacer primero como las lombrices, luego como los caracoles y por último como los cangrejos... (ibid., 326).

Huelga advertir que tales comparaciones figuraban ya en $E l$ mar del tiempo perdido: "Hicieron primero como las lombrices, después como los conejos y por último como las tortugas" ( $E r, 29-30$; véase también p. 45).

Así podría analizar detalladamente muchas comparaciones y aclarar unos aspectos más del arte de García Márquez. Sólo diré algo de la forma de las comparaciones. El propósito del autor es, generalmente, asimilar un personaje a un animal o dibujar una postura. Se comprende que la comparación revista las más de las veces la forma más sencilla: término 1 + como + término 2 (nombre de animal). Los ejemplos pululan:

"... nosotros seguimos viviendo como los burros" (p. 15).

Era liviana y acuosa como una lagartija (p. 33).

Rebeca era tan rebelde... que tenían que barbearla como a un becerro (p. 43).

...los ojos alumbrados como los de un gato (p. 44).

Encontró a Francisco el Hombre, como un camaleón monolítico (p. 51).

Llegaba a cualquier hora del día, como un tropel de cabras (p. 72). Tenía... el pelo corto y parado como las crines de un mulo (p. 83) ${ }^{49}$ ....apareció... macizo como un caballo (p. 131).

Úrsula ignoraba entonces la costumbre de mandar doncellas a los dormitorios de los guerreros, como se les soltaban gallinas a los gallos finos (p. 133).

... los abogados... revolotearon como cuervos (p. 186).

Amaranta Úrsula fue cerrando los dedos, contrayéndolos como un molusco (p. 332).

El escritor se vale de otras técnicas tan sencillas; entre los dos términos emplea el verbo parecer que, por ser cópula, señala un grado superior de asimilación al múndo animal:

49 Comparación recurrente, cf. Fun, 65. 
...fueron servidos por un bullicioso grupo de novicias de hábitos blancos, que parecían un revuelo de palomas asustadas por la lluvia (p. 154).

... una mano que más bien parecía una garra de águila (p. 203) .

Subieron a un cochecito que parecía un murciélago enorme (p. 250) .

Las comparaciones animales de García Márquez son funcionales a la par que poéticas. No tanto en el sentido de la expresión comparaison poétique que recoge Jean $\mathrm{Cohen}^{50}$, aunque bien podamos aprovechar los conceptos de écart o de anomalie structurale para explicar pasajes tales como: ". . . sintió la mano sin la venda negra buceando como un molusco ciego entre las algas de su ansiedad". Son poéticas sobre todo porque la asimilación progresiva de seres humanos y cosas a animales desemboca en un mundo mágico y fantástico poblado de entidades vitales con poderes misteriosos. Este mundo está aún más presente en los cuentos de Eréndira cuyas comparaciones se ciñen a la simbología imperante y a la ampliación de lo imaginario notados en estos textos. He aquí un par de ejemplos:

[Las mujeres] Andaban como gallinas asustadas picoteando amuletos de mar en los arcones... (Er, 54).

... miles de billetes de banco flotaban en el aire, aleteando como la mariposa (ibid., 66).

Ahora bien, en esta última comparación se trata de la falsa mariposa de papel que hemos visto arriba acabar en ser fantástico. E1 dinero, pues, es tan falso como la mariposa, tan ligero, tan impalpable, tan escurridizo como ella.

Se notarán igualmente la homogeneidad y simetría de algunas comparaciones de Eréndira:

se volvió a subir como un cangrejo (p. 85).

se bajó de la mesa como un cangrejo (p. 99)

Parecía [Eréndira] una lagartija envuelta en algodones (p. 119).

... sc la llevaron [a Eréndira] envuelta como un pescado grande y frágil capturado en una red lunar (p. 122).

La abuela... parecía una hermosa ballena blanca (p. 97).

[La abuela] est́á más viva que un elefante (p. 157).

\section{METÁForas aNIMALES}

La forma canónica de la metáfora en las obras de García Márquez es: sustantivo objeto del tropo + de o con + nombre de

50 Cf. JeAx Conm, "La comparaison poétique: essai de systématique", Langages, 1968, núm. 12, 43.51. 
animal. Tal secuencia, que figura, lo repito, en toda su obra, se propone animar la descripción, caracterizar a un personaje remitiendo a un rasgo animalista tipificado o subrayar la importancia de un detalle de la narración. La fórmula está ya perfectamente arreglada en La hojarasca: "...mirando [el doctor] a las mujeres con esos codiciosos ojos de perro" (p. 2l). La metáfora, que se va repitiendo a lo largo de los monólogos de Isabel (pp. 33, 41, 42), es para ella la representación emblemática del médico hasta su muerte: “. . sus vidriosos ojos de perro ahora sin codicia; de perro sin apetitos, muerto" (p. 61). Para su padre, el médico es ante todo una "voz de rumiante" vinculada al hecho de que, cuando apareció por primera vez en la casa del coronel, pidió para comer "hierba común, de esa que comen los burros" 51 .

En El coronel no tiene quien le escriba sigue el escritor empleando la forma canónica de la metáfora animal. Incluso la desarrolla en alegoría al contarnos la detención del coronel por el propio asesino de su hijo: "Se enfrentó a unos pequeños y redondos ojos de murciélago. En un instante se sintió tragado por esos ojos, triturado, digerido e inmediatamente expulsado" (p. 89) .

La frecuencia de estas metáforas animales aumenta considerablemente en Los funerales de la Mamá Grande y, sobre todo, en La mala hora, donde nos enteramos de la procedencia popular de muchas imágenes de García Márquez, quien no rechaza ni las metáforas animales más tópicas:

Tienes entrañas de burro (Fun, 30).

... una cura de burro $(M h, 175)^{52}$.

Se enfrentó a los diáfanos ojos de gato de su marido (Fun, 33) .

... le mostró en una sonrisa sus dientecillos de conejo (ibid., 53).

vio, junto al gramófono una muchacha que le miraba sin piedad, con una horrible expresión de perro meneando la cola (ibid., 101).

La necesidad tiene cara de perro $(M h, 165$; véase también $E r, 18)$. Don Sabas estaba pesando en la balanza su almuerzo de pajarito (Mh. 176).

Esta corriente metafórica popular y descriptiva invade literalmente las páginas de Cien años de soledad:

Un gitano... de manos de gorrión (p. 9); . . una secreta e implacable labor de hormiguita (p. 19); La lanza... arrojada con la fuerza de un toro (p. 26); . . con su cloqueante cacareo de gallina clueca (p. 43); La mulata adolescente, con sus teticas de perra (p. 51) ${ }^{\text {新; }}$

51 Hoj, 29, 59; 101, 102, 112.

52 Véase también CAS, 100, 328.

53 Metáfora que se repite en $E r, 104$. 
...su respiración exhaló un tufo de animal dormido (p. 68); ...el cuello de bisonte (p. 83); ... con unos ojos... que le daban a su rostro la ferocidad de una pantera (p. 165); ... su magnífico dominio de fiera en reposo $(177) ; . .$. el cabello redondo y liso rematado en las orejas con puntas de golondrinas (p. 318).

Esa corriente no se agota con los cuentos de Eréndira: “. . . tiernas y rosadas manos de buey de mar" (p. 52), metáfora claramente encaminada hacia lo imaginario, tanto como la de los "potentes brazos de oso" de la abuela (p. 161) que, junto a la sangre verde que derrama, da a entender que la vieja es un monstruo, una especie de dragón mitológico. He aquí otros ejemplos del mismo libro:

... una fragancia oscura de animal de monte (p. 68); . . su axila de animal de monte (p. 69); ... los malayos de piel de cobra (p. 77); ...palmadas de mulo (p. 92); ...el largo cabello de medusa (p. 105) ; ... .unos chillidos de animal azorado (p. 115); ... con la desidia invencible de un buey acostado (p. 124): ... un oficio de mula (p. 126); ...la peste de pellejo de chivo de las doscientas novias embarazadas (p. 129).

Otras fórmulas metafóricas confirman la importancia del lenguaje popular en la formación de las imágenes de García Márquez. Así cuando el coronel de la novela de 1961 asimila cosas imposibles a un elefante dorado, estamos al límite de la expresión popular estereotipada, si no lo es ya (Cor, 32). Lo mismo ocurre con los pajaritos de colores de que habla su mujer (ibid, 72). Insultos, apodos y expresiones familiares asociadas con el mundo animal abundan en todas las obras del novelista. Entre los insultos, citamos: ;animal! ${ }^{54}$; eres una mula (Mh, 188); eres burra (Fun, 47); eres un burro (Ibid., 56); mierda de perro (CAS, 32). Entre los apodos noto: El Cachorro (Hoj, 48; CAS, 130), La Elefanta (CAS, 219). Entre los giros familiares, apuntaré: Has echado a los cerdos lo mejor de tus creencias ${ }^{55}$, un gesto de espantar gallinas $(M h, 17)$, una escopeta de matar tigres (loe. cit.), incapaces de matar una mosca (CAS, 195), tener un sapo metido en la barriga ${ }^{56}$, etc...

Nuestro novelista acude también a otras fórmulas metafóricas registradas en los manuales de retórica. Se trata esencialmente del giro inverso de la forma canónica, o sea nombre de animal + de + sustantivo objeto de la metáfora, o bien de la asimilación

54 Fun, 57; Mh, 15; CAS, 216.

55 Hoi, 87; véase también $M h, 134$.

56 CAS, 166; es metáfora recurrente que aparece, con variantes, en otras obras de Garcia Márquez. 
completa de cualquier entidad a un animal mediante un verbo cópula:

... la muerte es un animal con pezuñas (Cor, 63) .

El único animal que se alimenta de carne humana es don Sabas (ibid., 86).

Los domingos huelen a animal crudo $\left(M h, 152^{5 \top}\right)$.

Era [la gitana] una ranita lánguida $(C A S, 35)$.

[José Arcadio] se convirtió en un enorme animal de trabajo (ibid., 102).

[Aureliano José] no era un niño asustado... sino un animal de campamento (ibid., 131).

...no podían alcanzarla ni los más altos pájaros de la memoria (ibid., 205) .

Eres demasiado malicioso para ser un buen murciélago (ibid., 332) . Todavía está muy biche $(E r, 104)$.

De ahí a la identificación completa formalmente indicada por la supresión de cualquier vínculo sintáctico, no hay sino un paso:

Si se hubiera casado con... la mosquita muerta (Hoj, 83).

Cuando entra el del revólver los cuervos [= hombres] se inclinan $\left(\right.$ Hoj, 130) ${ }^{58}$.

Cuando se duerma la ballena blanca $[=$ la abuela $]\left(E_{r}, 136\right)$.

Hasta el sentimiento amoroso del último Buendía para con Amaranta Úrsula logra identificarse con un terrible animal parasitario que habia incubado en el martirio (CAS, 332).

Esta clase de identificaciones no representa la última etapa de la metáfora animal en García Márquez. En efecto, en un pasaje de Cien años de soledad, la dinámica imaginaria rompe la barrera de la lengua común hasta crear nuevas formas. Partiendo de la asimilación del cuerpo de Amaranta Úrsula al de una comadreja o, más bien, anticipándola, inventa García Márquez el verbo comadrejear y el antónimo descomadrejear. En la misma frase, introduce el neologismo alacranear:

Amaranta Úrsula se defendía sinceramente, con astucias de hembra sabia, comadrejeando el escurridizo y flexible y fragante cuerpo de comadreja, mientras trataba de destroncarle los riñones con las rodillas y le alacraneaba la cara con las uñas...

Entonces empezó a huir con los labios apretados, sin renunciar a la lucha, pero defindiéndose con mordiscos falsos y descomadrejeando el cuerpo poco a poco... (CAS, 334-335).

5i Variante de la secuencia discursiva "el olor a animal crudo de los domingos".

¿8 Esta metáfora y la siguiente vienen anunciadas por comparaciones. 
La metáfora animal, pues, no se contenta con servir a la narración. Es propiamente creadora y desemboca en un mundo animalista fantástico cuyo burdel zoológico en Cien años de soledad es buena muestra (p. 333 ss.; cf. infra, pp. 83-84). Así también un llanto de becerro descomunal anuncia la muerte del Judío Errante presentado como una bestia mitológica (p. 292) .

Aquí tocamos un punto delicado que tal vez otros investigadores con mejores instrumentos de trabajo que los nuestros eluciden. Existe en la obra de García Márquez un verdadero sistema de la metáfora animal. Se puede decir de las metáforas animales del escritor colombiano lo que decía Gaston Bachelard acerca de la figura en general: “. . las metáforas no son simples idealizaciones que parten como cohetes para estallar en el cielo mostrando su insignificancia, sino $[\ldots]$ por el contrario las metáforas se atraen y se coordinan más que las sensaciones, al punto de que un espiritu poético es pura y simplemente una sintaxis de metáforas" 59 . He tratado de desprender unos sintagmas de la sintaxis metafórica de García Márquez. Quedan por investigar y explicar los sutiles y misteriosos mecanismos de relación.

\section{Animales míticos}

Algunos animales del bestiario de García Márquez, ya lo vimos, ocupan un puesto excepcional en sus novelas y cuentos. Mencioné las ratas y ratones de La mala hora, que revelan obsesiones del cura del pueblo. Recordaré la nube de mariposas amarillas que acompaña al Mauricio Babilonia de Cien años de soledad y nos guía hacia un mundo si no mítico, por lo menos alegorizado. Ya en La hojarasca (pp. 38-39) encontramos animales míticos sacados del caudal clásico y bíblico: el becerro de oro confundido con el vellocino del mito griego. Además se alude (p. 100) a "implacables bestias proféticas" que acorralan imaginariamente al médico.

Aquí hay que hablar de nuevo del gallo de pelea de El coronel no tiene quien le escriba, ya que, al fin y al cabo, el ave, "símbolo del orgullo local" (HARss, art. cit., p. 70) es el verdadero protagonista de la novela. Bien lo ha visto E. Volkening quien escribe: "El gallo, $[\ldots]$ en realidad es una quimera, un monstruo insaciable, la emplumada encarnación del anhelo que, compitiendo con el gusano en las entrañas del coronel, le devora el alma" ${ }^{\circ}$. El co-

59 G. Bachelard, La psychanalyse du feu, Paris, 1965, p. 179.

60 E. Volkening, "Los cuentos de Gabriel García Márquez o el trópico desembrujado", publicado juntamente con Is, pp. 38-39. Este estudio apareció primero en Eco, 1963, núm. 40, pp. 275-293. Completamente descaminada va (y no sólo en este punto) la crítica argentina Graciela Mituro, al relacionar 
ronel, su esposa y, finalmente, el pueblo entero no hacen sino vivir con las miras a este "fantasmagórico" (el adjetivo es de Volkening) gallo de pelea. Para él se sustrae el alimento más necesario, no pueden comérselo ya que no se mata a "una especie de ente mitológico o animal sagrado" (ibid., p. 41); él es, indirectamente, responsable de la muerte del hijo del coronel; sin embargo, es la razón de vivir del pobre héroe.

Plenamente mítico es el gallo de pelea de Cien años de soledad. Por él, mata el primer Buendía al propietario del gallo que se le opone. La víctima, Prudencio Aguilar, persigue a José Arcadio hasta en el sueño, haciendo que huyan los fundadores de Macondo. Luego se prohibe la cría de gallos de pelea que, por el mismo hecho, integran un mundo sagrado hasta que se echa abajo la prohibición por voluntad del segundo José Arcadio (CAS, 163). Desde aquel momento pesa la desgracia cada vez más sobre la familia.

En La prodigiosa tarde de Baltasar (Fun, 63-75), "la jaula más bella del mundo", objeto relacionado con el mundo animal, representa para Baltasar lo que el gallo para el coronel ${ }^{61}$. La lluvia de pájaros muertos, de que ya hemos hablado, alcanza a lo mítico por la exageración de un fenómeno natural. Quizá sea una trasposición de las ratas de La peste de Camus; con todo, estructuralmente, remiten a otros diluvios de la obra de García Márquez, los cuales, a su vez, enlazan con el diluvio bíblico.

En Cien años de soledad, se vale el autor de unos animales mitológicos más clásicos. Las sirenas, la ballena de Jonás, quizás la de $M o b y$ y $D k^{62}$, el elefante que vuela, los dragones y los caballos alados $^{63}$ son más bien secundarios, pero señalan la voluntad del autor de integrar en su novela cualquier categoría de la fauna fantástica y de llevar al lector hacia un más allá mítico. García Márquez suelta la imaginación al crear el primer burdel zoológico conocido:

...era un inmenso salón al aire libre, por donde se paseaban a voluntad no menos de doscientos alcaravanes que daban la hora con un cacareo ensordecedor. En los corrales de alambre que rodeaban la pista de baile, y entre grandes camelias amazónicas, había garzas

nuestro gallo con la figura de Cristo en sus muy discutibles Claves simbólicas de García Márquez, Buenos Aires, 1972, p. IIl. Se basa en el libro muy superficial de L. Arnould de Grémirly, Le coq, Flammarion, Paris, 1958.

61 Cf. E. Volkening, art. cit., p. 39.

62 Será un recuerdo escurridizo mezclado con fábulas de la misma clase; cf. "las prodigiosas fábulas de ... las ballenas que se alimentaban de barcos con tripulaciones", CAS, 269.

63 La misma fauna vuelve a a parecer en Er: "antiguas fábulas de sirenas" (p. 56), dragones (pp. 74, 95), ballenas (pp, 75-76), elefantes invisibles (p. 86). 
de colores, caimanes cebados como cerdos, serpientes de doce cascabeles, y una tortuga de concha dorada que se zambullía en un minúsculo océano artificial. Había un perrazo blanco, manso y pederasta, que sin embargo prestaba servicios de padrote para que le dieran de comer (CAS, 332-333).

La creación de entes híbridos, hombres y bestias a la vez, descubre aún más la intención del autor de colocar la acción en la región de los mitos. Además de un "hombre-víbora" (pp. 35-36, 40), de un niño-iguana ${ }^{64}$ y un niño-armadillo (p. 132), éstos dos sustitutos hiperbólicos del famoso niño con cola de cerdo, hay que citar el monstruoso retrato del Judío Errante, muy alejado de las inocentes representaciones de la literatura de cordel $^{65}$ o del personaje de la novela de Eugène Sue (Le Juif errant, 1844-1845). Ya viene anunciado en Los funerales de la Mamá Grande (p. 113): huele a macho cabrío y sacrifica corderos. Tal vez el Judío Errante sea, a este nivel, encarnación del demonio. La identificación se verifica en la novela de 1967: "Lo describió como un híbrido de macho cabrío cruzado con hembra hereje, una bestia infernal cuyo aliento calcinaba el aire y cuya visita determinaría la concepción de engendros por las recién casadas" (CAS, 291).

Sin embargo el ser mitológico par excellence de Cien años de soledad es el niño con cola de cerdo, fruto del incesto, maldición permanente que pesa sobre la familia de los Buendía y se realiza al final de la novela. Desde el punto de vista genético, no surge la idea de un niño con cola de cerdo desconectada de la obra anterior de García Márquez. En el cuento En este pueblo no hay ladrones (Fun, 53), se dice de un hombre que: "Parecía feliz, y era evidente que habría sido aún más feliz si además de las piernas y los brazos hubiera tenido una cola" 66 . "El animal mitológico que había de poner término a la estirpe" (CAS, 350) es como el pecado original de los Buendía (cf. ibid., 25), su obsesión fundamental, aunque no dejan de caer en la culpa cuyo castigo es el monstruo. La cola de cerdo estructura la obra; es, como dice muy bien Hugo Achugar, "el objeto que materializa la obsesión de la obra, siendo

64 Ya Carmen Arnau, El mundo mitico de Gabriel Márquez, Barcelona, 1971 , p. 88 , nota 37 , advirtió el juego "entre las palabras Iguarán", apellido de Úrsula, y "engendrar iguanas".

65 Véase por ejemplo el "Véritable portrait du Juif-Errant tel qu'il a été vu à Bruxelles, en Brabant, en 1774", reproducido en Roger Devigne, Le légendaire des provinces françaises à travers notre folklore, Paris, 1950, p. 170. Para España véase M. BATAILlon, "Les pérégrinations espagnoles des Juiferrant", BHi, 43 (1941), 81-122.

66 Véase también la comparación ya señalada en $M / h, 161$ : "como si arras. trara una cola enorme". 
el sello expresivo de un fatalismo palpitante que marca a los personajes" 67 .

En los cuentos de Eréndira se nota, según la feliz expresión de M. Vargas Llosa, la "hegemonía de lo imaginario"68. Es de esperar, pues, la presencia de seres míticos. En efecto, ahí están y bajo las formas más variadas. Ya hemos señalado (cf. supra, nota 63) los animales mitológicos de procedencia clásica. El héroe de $U n$ señor muy viejo con unas alas enormes es un híbrido que puede ser a la vez ángel y animal, "una criatura sobrenatural" o bien "un animal de circo" (Er, 13). Pero parece más bien cualquier ave con sus "alas de gallinazo grande" (p. 12), su postura de "gallina decrépita entre las gallinas absortas" (p. 13), sus nuevas plumas de "pajarraco viejo" (p. 19), su vuelo de "buitre senil" (p. 20). Aquí, pues, nos enfrentamos con el mito degradado, irrisorio, lamentable del hombre que vuela (ángel, Ícaro, ...), que vuelve a aparecer a modo de recurrencia y, probablemente, en su forma ideal, en el cuento de Eréndira y de su abuela desalmada (p. 116).

El primer texto de Eréndira alude a otros entes míticos. Así el funámbulo que compite con el "ángel", tiene alas de "murciélago sideral" (p. 14). Este "murciélago sideral" figura de nuevo en el cuento de Eréndira con sus dotes sobrenaturales y el calificativo "pavoroso" (p. 146). Otro mito es el de "la mujer que se había convertido en araña por desobedecer a sus padres [...]. Era una tarántula espantosa del tamaño de un carnero y con la cabeza de una doncella triste" (pp. 16-17) ${ }^{69}$ que reaparece en otro cuento (p. 146).

Como los cuentos "El mar del tiempo perdido" y "El último viaje del buque fantasma" se colocan en buena parte en el plano irreal los animales que ahí se mencionan tienen algo mítico. Así los caballos y las tortugas de la ciudad bajo las aguas, los toros de lidia del buque fantasma.

El momento decisivo de la vida de Blacamán el bueno ocurre cuando resucita un conejo, el cual se va "caminando por el aire" (p. 90) . Este tema de los animales terrestres o acuáticos que vuelan parece estimular la imaginación de García Márquez. Eréndira, dice, "se quedó fascinada con las franjas de luna de un pescado que pasó navegando en el aire de la tormenta" (p. 105). Esto ocurre al perder la joven la virginidad. Puede ser que en este caso se refiera García Márquez a la simbología tradicional que considera

67 H. Achugar, "Aproximación a Gabriel Garcia Márquez", Cuadernos de Literatura, Fundación de Cultura Universitaria, Paysandú, 1969, p. 27.

68 M. Vargas Llosa, op. cit., pp. 617-640.

69 Nótese la comparación con el carnero que permite medir concretamente el tamaño de la "tarántula" fantástica. Véanse también los "caimanes cebados como cerdos" (p. 22). 
el pez como representación de la pureza, o de la voluptuosidad, o del sexo masculino según dicen Freud y las tradiciones folklóricas ${ }^{70}$. De todas maneras aparece también "una mantarraya luminosa navegando por el aire" (p. 117) en una visión del abuelo de Eréndira descrita por la abuela dormida. Al revés, animales acuáticos caminan por la tierra (cf. supra, p. 14), tales como esas "esponjas vivas que después andaban caminando por dentro de las casas, gimiendo como enfermos de hospital" (p. 152), de que habla la abuela en otro delirio nocturno.

En los cuentos de Eréndira parece que García Márquez, siguiendo el camino descubierto en Cien años de soledad, va creando su propia fauna mítica que adquiere cada vez más autonomía. Sin embargo, sus animales fantásticos se parecen a monstruos conocidos, especialmente a los de El Bosco, lo que plantea la cuestión de una posible interpretación ocultista. El propio García Márquez nos guía en este camino al descifrar contradictoriamente otro sueño de la abuela en que entra en juego "un pavorreal en una hamaca blanca". "Los pavorreales de los sueños son animales de larga vida", le dice Eréndira (p. 160). En realidad, es un "aviso de la muerte" (p. 161).

Después de haber hojeado rápidamente el bestiario de Gabriel García Márquez, después de haber establecido el catálogo de las varias funciones de los animales reales o imaginarios y el de las comparaciones y metáforas animales, habría que escudriñar su motivación profunda. Me falta espacio para emprender esta investigación imprescindible y probablemente esencial. Sospecho que los resultados serían curiosos y desembocarían en un horizonte aún más amplio que el que limita las obras de García Márquez. Al redactar este trabajo no hice sino esbozar unas vías explicativas que ahora resumo.

La obsesión por el mundo animal del novelista colombiano pudo darse parcialmente (y hasta Cien años de soledad incluso) por un doble determinismo: el determinısmo biográfico llevó al escritor, nacido en un pueblecito colombiano, a integrar en su imaginación la convivencia de los hombres y de los animales, inevitable en una sociedad rural; actuó luego el determinismo literario en la selección de un pueblo como lugar y protagonista novelesco. Ambos son, en realidad, uno solo: al inventar Macondo, busca García Márquez el pueblo de su infancia.

Esta clase de elucidación no puede, claro está, satisfacer los requisitos de una crítica exigente. Habría que relacionar el bestiario del colombiano con el hecho de que, en todas partes y en

70 Véase por ejemplo, Max J. Fruedländer y Mra Cinotr, Jérôme Bosch, Paris, 1967, p. 119. 
todo tiempo, los animales -o por lo menos algunos de ellossegún las civilizaciones, se consideran como receptáculos de una fuerza mágica, de poderes misteriosos. Habría que investigar, pues, en la literatura popular y en las tradiciones folklóricas. Habría que acudir a los bestiarios medievales y modernos (entre los últimos a los de Apollinaire, Ramón Gómez de Serna o Julio Cortázar). Habría que tener en cuenta los vínculos posibles con las mitologías "clásicas" del mundo entero, las cuales tienen un buen caudal de seres híbridos (faunos, sátiros, centauros, sirenas, Quetzalcóatl, Horus, Anubis, Minotauro, etc...). El niño con cola de cerdo de Cien años de soledad, en este caso, no sería sino la copia irrisoria de un arquetipo mítico.

Interesante sería también buscar en los datos de la antropología cultural. Basándose en el libro de C. LÉvr-STrauss, Les structures élémentaires de la parente ${ }^{i 1}$, Carmen Arnau advirtió que el temor del híbrido es consecuencia de la prohibición del incesto en las sociedades primitivas ${ }^{72}$.

Para terminar, creo que estudios generales sobre lo imaginario y el psicoanálisis nos enseñarían mucho sobre la obsesión animal73. Este género de investigaciones iluminarían algunos rincones todavía oscuros de la obra de Gabriel García Márquez.

Jacques Joset

Universidad de Amberes. U. I. A.

71 C. Lévi-Strauss, Les structures élémentaires de la parenté, Paris, 1949.

72 C. Arnau, op. cit., p. 87. Véase también el excelente trabajo de C. Bouché, "Mythe et structures dans CAS de Gabriel García Márquez", $M R o$, $23 / 24$ (1973-74), pp. 237-249.

73 Véase como aplicación el comentario de Sartre a la relación entre las metáforas animales del lenguaje amoroso y "la postulation vers Satan", según Baudelaire (J. P. SARTre, Baudelaire, Paris, 1947, p. 44). También sería útil, pienso yo, comparar la estructura y función del "bestiario" de García Márquez con los de otros mundos animales imaginarios, como el de Julio Cortázar o de Gómez de la Serna, por quien el escritor colombiano siente una "intensa admiración" (cf. M. Fernández Braso, La soledad de Gabriel Garcia Márquez, Barcelona, 1972, p. 111). 